\title{
Sentidos alegóricos da dialética sujeito-objeto na modernidade: o duplo em "A Caverna", de Saramago
}

\author{
Mariana Vieira Cardoso ${ }^{\mathrm{i}}$ \\ Daniel Nunes Santos ${ }^{\text {ii }}$
}

\section{RESUMO}

O presente artigo apresenta uma interpretação da obra A Caverna (2000), do autor português José Saramago, baseada no seu caráter alegórico e na sua possível ilustração do movimento histórico de constituição da subjetividade no âmbito da modernidade. Para isso, esta pesquisa se apoia, sobretudo, nas reflexões de Bakhtin (2003) acerca da formação da subjetividade a partir da relação dialética eu e outro, relação que aborda o fundo temático literário: o duplo, antes explorado em diversos exemplares da literatura ocidental. A partir dessas e outras ferramentas críticas e teóricas, interpretamos o destino de Cipriano Algor, protagonista de A Caverna (2000), como ilustrativo do modo como o sujeito moderno é silenciado e marginalizado no interior da dinâmica capitalista a partir da dialética sujeito-objeto.

Palavras-chave: A caverna; José Saramago; Duplo; Alegoria; Alteridade.

\begin{abstract}
This article presents an interpretation of the work A Caverna (2000), by Portuguese author José Saramago, grounded on its allegorical feature and on its possible illustration of the historic movement of subjectivity formation in the scope of modernity. To that end, this research uses Bakhtin's (2003) reflections on the formation of subjectivity from the dialectic relation of self and other, a relation that addresses the literary thematic fund: the double, previously explored in several examples of Western literature. From these and other critical and theoretical tools, we interpret the destiny of Cipriano Algor, protagonist of A Caverna (2000), as an illustration of how the modern subject is silenced and marginalized within the capitalist dynamics from the dialectic subjectobject.
\end{abstract}

Keywords: A caverna; José Saramago; Double; Allegory; Otherness.

\footnotetext{
i Possui graduação em Licenciatura em Letras pela Universidade do Estado do Amazonas. Atualmente, como mestranda do Programa de Pós-graduação em Letras e Artes (PPGLA-UEA), é membro do grupo de pesquisa Múltiplas Linguagens, Semiótica e Discurso na Contemporaneidade - SDiscon, no qual desenvolve pesquisa acerca do "Léxico de mulheres vítimas de violência na cidade de Manaus". https://orcid.org/0000-0003-1523-9519 | marianavicardoso@gmail.com

ii Possui bacharelado em Letras pela Universidade do Estado do Rio de Janeiro (UERJ), é mestrando no Programa de Pós-Graduação em Letras e Artes na Universidade do Estado do Amazonas (PPGLA-UEA) e bolsista pela Capes, por onde atua na linha de pesquisa "teorias, críticas e processos de criação" com pesquisa acerca de "Borges e a forma literária reflexiva: limites da representação". https://orcid.org/0000-0001-8878-8637 | danielns1987@ gmail.com
} 


\section{INTRODUÇÃO}

A partir do século XVIII no âmbito do mundo ocidental, a ideia do duplo encontra-se em estreita ligação com o pensamento da subjetividade ao servir como possível ilustração da dialética sujeito-objeto. De acordo com Bravo (1998), se até então o que prevalecia era uma tendência à unidade na concepção de mundo, a partir do final do chamado Século das Luzes o duplo passa a aderir a uma nova concepção em que prevalece a heterogeneidade na estética da representação literária. Quando a questão da alteridade se evidencia de maneira refletida, por exemplo em um espelho, "o eu e o outro se confundem com a identidade dupla, não duplicada, mas singularizada segundo sua própria subjetividade" (CAVALHEIRO, 2015 p. 77). Deste modo:

\footnotetext{
(...) no outro - que, por vezes, é o mesmo - o eu busca substância para configurar sua subjetividade. Essa forma de pensar a alteridade, por sua vez, será ampliada, sobretudo na virada do século XIX para o XX, à quebra da unidade subjetiva, avançando à fragmentação do eu, sem limites definidos, $\mathrm{o}$ que viria a caracterizar, ao menos em termos estéticos, a modernidade literária. (CAVALHEIRO, 2015, p. 76)
}

Paulo Bezerra, em prefácio à segunda edição brasileira de Problemas da poética de Dostoiévski (2002 [1972], p. XI), afirma que "a ideia central do pensamento de Bakhtin é a ideia do outro, ideia da familiarização, do entendimento, do diálogo. Neste sentido, sua estética humanística pode ser sintetizada no par comunicativo 'eu-outro"”. Este par comunicativo de Bakhtin (2003) pode ser visto em analogia à concepção de duplo que é construída a partir de sentidos alegóricos da dialética sujeito-objeto, ou seja, a partir de relações que, por vezes, objetificam o outro, seja por o eu projetar-se nele ou seja por este $e u$ silenciá-lo. Essa dialética, ainda segundo Bakhtin (2003b), é construída a partir do caráter alegórico presente em cada discurso. Portanto, sob esta perspectiva, realizaremos a leitura d'A caverna, de Saramago.

\section{O DUPLO EM A CAVERNA DE JOSÉ SARAMAGO}

Ao longo dos séculos o duplo foi fonte de inspiração para a história, filosofia literatura e mitologia, por exemplo. A concepção do duplo aparece nos escritos platônicos, no mito de Pigmalião, em Goethe, em Poe, em Maupassant, em Dostoiévsky 
e em Shakespeare. Nesta lista também pode-se encontrar escritos de Machado de Assis, Jorge Luis Borges e Guimarães Rosa, por exemplo. Assim, o duplo tornou-se uma espécie de fundo temático para que variados universos se desenvolvessem, seja a partir do símbolo do espelho como no mito de Narciso, ou através de duplicações como em $O$ homem duplicado, de Saramago (2008).

Há, ainda, desde o mito da caverna de Platão, o duplo como representação de outros mundos. Esse tipo de duplo aparece tanto em obras literárias como Alice no País das Maravilhas, de Lewis Caroll (2012), quanto em alguns mitos, a partir da dualidade de figuras que representam universos paralelos, como o céu e o inferno na mitologia cristã, ou a terra assistida por Zeus e o submundo de Hades na mitologia grega. Sob esta ótica, as fronteiras entre esses mundos refletem as fronteiras existentes na concepção do sujeito e na relação eu-outro, pois, a partir da exterioridade presente nos mundos apresentados é que está a convivência - e constituição - do eu a partir do outro:

\begin{abstract}
A separação, o desligamento, o ensinamento como causa central da perda de si mesmo. Não se trata do que ocorre dentro, mas na fronteira entre a minha consciência e a consciência do outro, no limiar. Todo o interior não se basta a si mesmo, está voltado para fora, dialogado, cada vivência interior está na fronteira, encontra-se com outra, e nesse encontro tenso está toda a sua essência. (...) Ser significa conviver. Morte absoluta (o não ser) é o inaudível, a irreconhecibilidade, o imemorável (...). Ser significa ser para o outro e, através dele, para si. O homem não tem território soberano, está todo o sempre na fronteira, olhando para dentro de si ele olha para o outro nos olhos ou com os olhos do outro. (BAKHTIN, 2003b, p. 341, grifos do autor)
\end{abstract}

De acordo com Chauí (2000), a alegoria da caverna platônica remete à divisão do mundo em dois: um mundo de aparências, de transformações, do "devir", e um (outro) mundo do ser, da identidade e permanência. Nessa perspectiva, o duplo não é um reflexo que simbolize um conflito que ocasione a morte - como no mito de Narciso - ou a inquietação de, por exemplo, Tertuliano Máximo Afonso em O homem duplicado, de Saramago (2008). O duplo, quando utilizado para apresentar mundos ambivalentes que convivem e que, por vezes, competem entre si, representa a formação social em que o eu está imerso, sendo um tecido que perpassa a representação da realidade e reflete cronicamente a sociedade em que se está inscrito.

Em A Caverna (2000), Saramago utiliza o mesmo arquétipo de duplo do mito da caverna de Platão, simbolizando a divisão do mundo em dois: 1) mundo de aparências e 2) mundo de permanência. No entanto, o escritor português vai além de Platão ao 
promover relações também duplas entre as personagens de seu romance, construindo símbolos e críticas sociais a partir delas. Bakhtin (2003b) ilustra que esse tipo de conduta ocorre quando "na autoconsciência do herói penetra a consciência que o outro tem dele, na autoenunciação do herói está lançada a palavra do outro sobre ele" (BAKHTIN, 2003b, p. 240).

Para exemplificar nossa reflexão lancemos o olhar ao personagem principal do romance, o oleiro Cipriano Algor, personagem que vive no campo a partir da produção e venda de louças de barro e descobre, ainda no início da narrativa, que o "Centro" lugar em que funciona o comércio - não está mais interessado em comprar suas louças, pois há uma novidade no mercado: louças de plástico. O barro, que atua como figuração do universo de Cipriano e da personalidade construída a partir de suas vivências, representa o mundo do ser, da permanência, do campo. O plástico simboliza o universo oposto, referente à modernidade, às aparências vividas pelo "Centro". É a partir dessa oposição que analisaremos a obra selecionada, pois, a narrativa que se desloca entre esses dois universos e promove a imersão dos personagens nestas ambivalências. Mas antes de verificarmos de que forma esta perspectiva se constrói na narrativa, é preciso que olhemos melhor para o conceito de duplo e sua relação com a dialética sujeitoobjeto.

\section{O DUPLO: A RELAÇÃO EU-OUTRO, UM JOGO DE ESPELHOS - DIALÉTICA SUJEITO-OBJETO}

De acordo com Baudrillard (1988), a questão da alteridade se constitui a partir da relação eu-outro. Essa relação é uma experiência que compreende interação, dependência e reconhecimento. Assim, a construção do $e u$ - enquanto sujeito, indivíduo - é constituída apenas em contato com o outro (podendo ser outro indivíduo, a coletividade ou, ainda, o próprio $e u$ ). A partir do conceito de alteridade, podemos desenvolver a perspectiva de duplo. Este não se trata necessariamente da duplicação de um sujeito, mas tal como a identificação de alguém por meio de um espelho, o eu não apenas se reconhece e interage com o outro, como também se (re)configura pondo-se no lugar deste outro para se complementar e retornar a si. Como afirmamos, trata-se também de uma relação de dependência, por seu percurso ser duplo, visto que o eu só se 
reconhece como sujeito diante da visão que o outro tenha dele. Podemos ilustrar esta explicação do duplo a partir de um movimento cíclico:

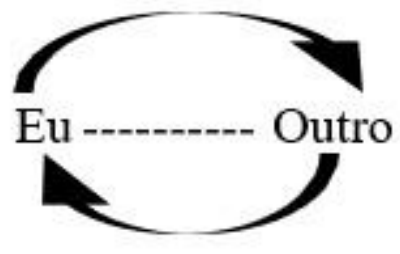

Bakhtin (2003), em "O autor e a personagem na atividade estética", aponta que a relação criadora do autor com a personagem é construída sob o princípio de exotopia. A partir deste princípio tanto o autor quanto a personagem são consciências, uma está fora da outra, podendo enxergar apenas a outra consciência - em comparação com a sua como um todo completo. O primeiro movimento desse princípio estético é a compenetração: neste movimento o autor-criador vivencia o espaço social de sua personagem, coincidindo com ela. Após a compenetração, deve haver o retorno a si mesmo para, a partir de seu lugar, complementar o horizonte da personagem e o do próprio autor-criador. Assim, Bakhtin (2003) esclarece que é através deste acabamento do outro que há o acabamento do eu. Desse modo, na atividade estética sempre existirá "um movimento duplo: o de tentar enxergar com os olhos do outro e o de retornar à sua exterioridade para fazer intervir seu próprio lugar (...)”(AMORIM, 2004, p. 102).

Junto com Bakhtin (2003), ainda em "O autor e a personagem na atividade estética", consideramos que o eu configura sua subjetividade através do contato com subjetividades outras, advindas do espaço social, criando nessa relação singularidades que funcionam como espelhos. Quando o locutor assume o papel discursivo "eu", confronta-se com outro $e u$, reconhecendo-se em uma oposição que o configura como sujeito a partir da interação, tal qual um jogo de espelhamento linguístico. Assim, a língua é uma ferramenta para a construção da intersubjetividade. Bakhtin (2003b) observa que a linguagem é uma realidade social avaliativa, ou seja, uma criação dialógica que cria o espaço possível para a relação eu-outro, pois apenas na linguagem há a possibilidade de um sujeito intitular-se como o eu do discurso e isto só ocorre porque este sujeito identifica outro, seu destinatário. 
Por outro lado, segundo Bravo (1998), o duplo, do alemão Döppelgänger, significa "aquele que caminha ao lado" ou "companheiro de estrada", e se trata de uma ideia que marca presença desde a mitologia grega até a judaica, pré-colombiana, indiana e cristã. Para Chevalier e Gheerbrant (2005 [1982] p. 353), a imagem simbólica do duplo está relacionada à oposição, à dualidade, à multiplicação bipolar, ao conflito, ao desdobramento, ao combate e ao progresso. O duplo se vincula ao número dois que, por sua vez, simboliza "o outro enquanto que outro. Da mesma forma, se a personalidade se afirma opondo-se, como já foi dito, dois é o princípio motor da individualização" (CHEVALIER; GHEERBRANT, 2005 [1982], p. 346). É Bravo (1998) quem explica que essa dualidade e individualização se dá devido ao caráter mimético do duplo, pois o $e u$, ao desdobrar-se, cria cópias que desenvolvem subjetividades outras - diferentes deste $e u$ antes da fragmentação - individualizando-se e criando identidades próprias, não se prendendo à mesma essência, mas constituindo-se a partir dela, aos olhos dela, tornando-se outro.

Bakhtin (2003) evidencia que por vezes o movimento duplo realizado na relação eu-outro não se completa devido a uma das partes - o eu ou o outro $e u$, coincidentes ou não - fechar-se num processo de marginalização e silenciamento de um dos enunciatários. Quando este silenciamento é completo caracteriza-se o que o pensador russo chama de dialética sujeito-objeto. Essa dialética, ainda segundo Bakhtin (2003), é construída a partir do caráter alegórico presente no discurso. É sob essa perspectiva que poderemos agora nos debruçar sobre A caverna, de Saramago.

\section{A AlEgoria E A MODERNIDAdE A PARTIR DO DUPLO EM A CAVERNA, DE SARAMAGO}

De acordo com Maria Alzira Seixo (1987), o procedimento de alegorização é uma das marcas fundamentais nas obras de Saramago. Em A caverna, a alegorização se dá em contato e contraste ao conhecido mito platônico, numa possível atualização desse mito para o âmbito da modernidade. O mecanismo significativo da dinâmica alegórica nos possibilita fazer uma leitura d'A Caverna como uma importante narrativa que retrata o caráter social de seu tempo. É sob essa perspectiva que vemos a tensão e o sofrimento de Cipriano Algor, que tem sua força de trabalho e seu meio de sustento 
inutilizados no interior da dinâmica capitalista, na qual o mercado dita as regras de aceitação e inserção do humano no que Baudrillard (1988) chamaria de um "sistema de objetos". Assim como em outros romances, Saramago se vale dos recursos da escrita para a construção significativa de uma representação alegórica. A não marcação de pontuações na fala das personagens pode ser lida neste caso como o que Stuart Hall (2003) denominaria de processo de construção da identidade na pós-modernidade, visto que as vozes se misturam e por vezes os diálogos são cíclicos, fazendo com que diferentes personagens expressem os mesmos pontos de vista, demarcando como que uma homogeneização de identidades no interior da dinâmica capitalista, representada então pela figura do "Centro" no romance, verdadeiro antagonista que engole, marginaliza e corrompe as personagens.

Assim, a escrita de Saramago pode ser lida, ainda, como um reforço à multiplicação de sentidos conflituosos, através da tensão dialética entre um ideal social humanístico - o homem como um ser realizado que é ouvido e compreendido - e a consciência da impossibilidade de escapar deste universo contemporâneo de imagens e representações. Baudrillard (1988) salienta que esta dialética humanística social é gerada a partir de um sistema moral ilusório que ocasiona um processo de alienação social. Esta alienação faz com que o $e u$, ao ser marginalizado e corrompido por esse sistema, perca parte de sua sensibilidade ao se relacionar com o outro.

Para exemplificar nossa leitura, podemos destacar o trecho em que o cão Achado é severamente punido com tapas e pontapés por ter ido brincar com Cipriano enquanto ele retirava alguns bonecos de barro do forno. Neste trecho de A caverna (2000), o cão Achado toma a palavra e é ele quem reflete sobre a resposta violenta diante de sua brincadeira: “o cão Achado só daqui a pouco reparará que os donos levam umas figuras de barro em equilíbrio sobre umas tábuas, (...) imagina-se o desastre que sucederia se não me tivessem travado a tempo às efusões." (SARAMAGO, 2000, p. 181, grifo nosso). Neste trecho, portanto, é o outro - Achado - quem estabelece uma convenção discursiva que compreende o $e u$, devido a seu estado de apreensão e sofrimento diante de sua situação financeira e da oportunidade que os bonecos de barro representavam.

Sob este viés, o universo literário de Saramago, para Maria Alzira Seixo (1987), apresenta uma arquitetura discursiva bipolar "mantendo como resultado uma tensão ideológica, ou a sua conversão através da ironia, da conclusão (ou abertura) claramente 
moralizante" (SEIXO, 1987, p. 18). Ainda em conformidade com Maria Alzira Seixo, observamos que as obras de Saramago são veículos históricos, ou seja, apresentam marcas temporais como em uma crônica, tornando-se atemporais, entretanto, no seu vínculo com vivências que podem ser especificadas ao nível de sua concretude material. Assim, Saramago se vale da literatura como uma ferramenta de reflexão do homem sobre si mesmo e seu lugar no mundo. Em A caverna, essa reflexão está atrelada a uma série de questões próprias da modernidade, em que se torna onipresente o mundo dos objetos e a objetificação dos seres, abrindo espaço para o aumento da relevância social das imagens, dos simulacros e das simulações.

Cipriano Algor pode ser visto, assim, como uma triste ilustração da inutilização da mão de obra no interior da dinâmica capitalista. Relembremos que, no romance, ao Cipriano retornar para casa e contar para sua filha Marta sobre a recusa do Centro em comprar suas louças, a filha tem a ideia de que seu pai ofereça bonecos de barro, bonecos que representem algumas profissões. Os dois selecionam seis modelos para reproduzi-los: o bobo, o palhaço, a enfermeira, o esquimó, o mandarim e o assírio de barbas. Após diversas tentativas, Cipriano apresenta o resultado para os compradores. Estes aceitam metade dos bonecos e, após esta metade, rejeitam completamente a proposta, fazendo com que Cipriano Algor perca completamente as esperanças de continuar com seu trabalho como oleiro, trabalho este que alimentou gerações de sua família, sendo a única ocupação que o protagonista dominava. Podemos afirmar que a rejeição do Centro aos produtos do oleiro se insere no mecanismo significativo de uma tragédia alegórica que pode ser lida como a expressão do abandono e marginalização do homem diante do reinado das imagens e dos objetos na sociedade capitalista.

\footnotetext{
Do que realmente aqui irá tratar, sem grandeza nem dramas, é de levar ao forno e cozer meia dúzia de estatuetas, insignificantes para que reproduzam, cada uma delas, duzentas suas insignificantes cópias, há quem diga que todos nascemos com o destino traçado, mas o que está à vista é que só alguns vieram a este mundo para fazerem adões e evas ou multiplicarem pães e peixes. (SARAMAGO, 2000, p. 173)
}

De acordo com Chauí (2000), há espaços intermediários entre os universos apresentados a partir de duplos. Por exemplo, há o duplo céu e inferno na mitologia cristã e, como espaço intermediário, há o purgatório. O purgatório reforça as distinções entre o céu e o inferno, reafirma suas simbologias e funciona como uma fronteira capaz 
de intensificar o caráter cíclico da ambivalência do duplo. Em "A caverna", entre o campo, habitado por Cipriano Algor, e o Centro há uma estrada intermediária que serve de ambiente para diversas reflexões que reforçam a representação alegórica construída na narrativa. Mais próximo do espaço de convívio de Cipriano, há a "Cintura Verde":

\begin{abstract}
A região é fosca, suja, não merece que olhemos duas vezes. Alguém deu a estas enormes extensões de aparência nada campestre o nome técnico de Cintura Agrícola, e também por analogia poética de Cintura Verde, mas a única paisagem que os olhos conseguem alcançar nos dois lados da estrada, cobrindo sem solução de continuidade perceptível muitos milhares de hectares, são grandes armações de tecto plano, tectangulares, feitas de plástico de uma cor neutra que o tempo e as poeiras, aos poucos, foram desviando ao cinzento e ao pardo. Debaixo delas, fora dos olhares de quem passa, crescem plantas. (SARAMAGO, 2000, p. 12)
\end{abstract}

Após a passagem pela "Cintura Verde" há, antes de chegar ao Centro, a "Cintura Industrial”, que assim como o espaço anterior é marcado por características que reforçam a proximidade com o Centro e a construção alegórica da narrativa:

Deixaram a Cintura Agrícola para trás, a estrada, agora mais suja, atravessa a Cintura Industrial rompendo pelo meio de instalações fabris de todos os tamanhos, atividades e feitios, com depósitos esféricos e cilíndricos de combustível, estações eléctricas, redes de canalizações, condutas de ar, pontes suspensas, chaminés lançando para a atmosfera rolos de fumos tóxicos, gruas de longos braços, laboratórios químicos, refinarias de petróleo, cheiros fétidos, amargos ou adocicados (...) ninguém sabe o que se estará produzindo ali. (SARAMAGO, 2000, p. 13)

Para chegar ao Centro de forma mais rápida, o narrador afirma que Cipriano Algor e Marçal Gacho tomam um "traçado confuso" (SARAMAGO, 2000, p. 17), trecho este que reafirma as demais passagens narrativas no interior da alegoria, entendida como uma construção ao mesmo tempo linguística, narrativa e cênica, visto que os espaços são descritos de forma muito detalhada e com uma carga imagética que reafirma a representação alegórica do romance. Podemos esquematizar os seguintes espaços evidenciados a partir do duplo Olaria-Centro: 


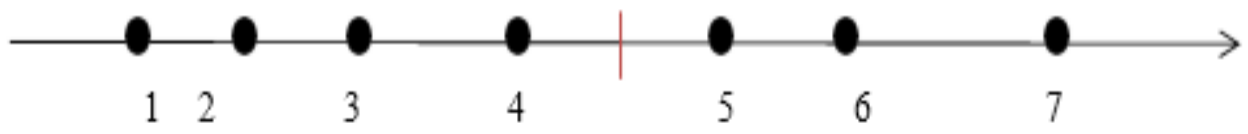

O espaço número 1 é a Olaria, representa o universo do ser como antes explicado; os espaços números 2 e 3 são próximos à Olaria, respectivamente, o cemitério em que a esposa de Cipriano está enterrada e a casa de Isaura, futura namorada de Cipriano. Estes ambientes são retratados como pertencentes ao universo da Olaria, ou seja, são espaços em que a narrativa não apresenta oposição à identidade social das personagens e sim um complemento à sua subjetividade. O espaço número 4 representa a Cintura Verde e marca o último espaço mais próximo ao universo da Olaria. O eixo 5 da reta representa a Cintura Industrial, o número 6 a periferia da cidade, sendo o eixo 7 o Centro. Podemos apontar que a identificação do eu está na Olaria e o outro, neste caso o antagonista que reprime o eu, está no Centro. Deste modo, o eu está para a Olaria assim como o outro está para o Centro. Não há aqui a realização de uma relação de alteridade, visto que o $e u$ é reprimido pelo outro e o outro não enxerga o $e u$ como um indivíduo de voz ativa. Realiza-se assim a objetificação deste $e u$, tal como ilustrado por uma das falas do protagonista Cipriano Algor: "pensei que não há grande diferença entre as coisas e as pessoas, têm sua vida, duram um tempo, e em poucos acabam, como tudo no mundo" (SARAMAGO, 2000, p. 62).

Em conformidade com a concepção de Marc Augé (1994), podemos ver no conceito de "não-lugares" uma analogia com os espaços intermediários entre a Olaria e o Centro, que representariam as mudanças sofridas pelo sujeito e a multiplicidade identitária da modernidade. "Se um lugar pode se definir como identitário, relacional e histórico, um espaço que não pode se definir nem como identitário, nem como relacional nem como histórico definirá um não-lugar, (...), espaços esses não são em si antropológicos" (AUGÉ, 1994, p. 73). Em nossa leitura, assim como a Olaria está para a afirmação da identidade subjetiva, o Centro representa a negação dessa identidade.

Para melhor expor nossa perspectiva, retomemos que, após a rejeição das louças e bonecos de barro fabricados pelo oleiro, Marçal Gacho, Marta e Cipriano deixam a 
casa em que moravam e passam a residir no Centro. Entre os diversos elementos significativos expostos durante esta parte da novela, destacamos que o Centro se caracteriza por não ter janelas, como um grande shopping center no qual as pessoas residem e pagam altos preços para entrarem em salas em que se imita a sensação da luz do sol ou de um céu nublado. Para Chevalier e Gheerbrant (2005), as janelas remetem à liberdade e aos olhos do sujeito, por isso a falta de janelas no Centro reforça a ideia de aprisionamento, alienação e objetificação. Nesta parte da narrativa, Cipriano começa a buscar lugares obscuros que provavelmente estejam em partes não visitadas do Centro e assim ele encontra uma caverna com corpos e decide que não morará mais naquele espaço. Ao regressar para a Olaria, Cipriano se envolve afetivamente com Isaura Estudiosa e recebe a filha e o genro novamente, pois estes também perceberam o caráter devorador do Centro. Como forma de resistência ao silenciamento imposto pelo Centro, há no desfecho uma retirada de cena das personagens. Ainda não sabendo onde residirão, acompanhadas do cão Achado, saem da cidade na furgoneta de Cipriano Algor e, ao passarem pela entrada do Centro, veem um cartaz e adivinham o que ele dizia: "Brevemente, abertura ao público da caverna de Platão, atracção exclusiva, única no mundo, compre já a sua entrada" (SARAMAGO, 2000, p. 350). Os dizeres do cartaz exposto na entrada do Centro são a última frase contida no romance, o que reforça a construção alegórica - narrativa e cênica - arquitetada ao longo da novela, fechando o ciclo dos dois universos com a evasão dos sujeitos em busca de um novo espaço - físico e social.

\section{CONCLUSÃO}

Retornando ao movimento cíclico da relação eu-outro, que segundo Bakhtin (2003) constitui a alteridade, concluímos que o sujeito, representado alegoricamente pelas personagens de A caverna (2000) de Saramago, é impossibilitado de estabelecer em sua integridade a relação cíclica na qual destacamos que o eu constitui sua identidade a partir do outro, enquanto este outro, paradoxalmente também um eu, realiza o mesmo movimento, indo para o outro - como em um espelho - e retornando a si para complementar sua visão de mundo. $\mathrm{O}$ ambiente hostil retratado no romance de Saramago dá ensejo à marginalização do $e u$ - representado por Cipriano Algor, Marta e 
Marchal Gacho -, que ao estabelecer relação com o outro - o Centro - sofre constante silenciamento e marginalização.

De acordo com esta leitura, o Centro funciona como um ambiente alienador no qual o eu se apequena e se anula em suas potencialidades de constituição de si próprio. Em outras palavras, o Centro, enquanto outro, estabelece uma relação unilateral com seus moradores e visitantes. Neste ambiente há, em uma espécie de alegoria ao capitalismo, uma homogeneidade forçada, visto que apesar de os moradores poderem caminhar aparentemente livres, há muitas salas proibidas, não há janelas, não há contato com o mundo exterior e, para aqueles que optam por não residirem no Centro, não há empregos, as moradias são provisórias e há a necessidade de alguns indivíduos cometerem furtos para obterem alimentos.

No Centro, também não há diálogos entre os indivíduos, mas há anúncios por todas as paredes. Como antes dito, não há janela, mas há salas que promovem simulações de tempestades, por exemplo. No Centro, há a possibilidade de resistência por meio de uma evasão, mas há a impossibilidade de trabalho no ambiente que fica em seu entorno, espaço que antes era o lar de Cipriano e de seus ancestrais. Deste modo, no mercado representado pelo Centro, tudo é comprável e vendível: até mesmo esqueletos em uma caverna, como citado anteriormente. Assim, este grande polo que é o Centro não se modifica a si próprio e nem é modificável pelos indivíduos que vivem nele. Mas ele promove drásticas modificações nos outros que com ele se relacionam.

Sob esta ótica, o Centro é uma força autônoma que constitui a si mesmo sem necessariamente depender de relações individuais que cada indivíduo projeta em relação ao par comunicativo eu-outro. Por isto o ciclo eu-outro não se conclui em relação ao Centro. Os indivíduos que se relacionam ao Centro são modificados, perdem partes de identidade e de suas referências de mundo, são identificados ou como mão de obra ou como consumidores.

O Centro impõe a perda de Cipriano de até mesmo ser oleiro porque proíbe que ele venda seus produtos a qualquer outro comprador das proximidades de seu monopólio. Mas o discurso é terminado a partir da imposição desta perda, não há um diálogo, não uma modificação mercadológica ou uma atualização. Há o apagamento de artesãos e a promoção da indústria, conforme representado a partir do advento do plástico e das características da Cintura Agrícola e da Cintura Industrial. Deste modo, o 
Centro se apresenta durante a narrativa como um monopólio imutável, ainda que de fato ele o seja, não há evidências desta possibilidade de mutação na narrativa.

Assim, o indivíduo é constituído em função do Centro, mas o Centro não é constituído em função do indivíduo. O desfecho da narrativa, com Cipriano e sua família dentro da furgoneta abandonando o ambiente monopolizado pelo Centro, conforme explicado na seção 03, pode ser lido justamente como um percurso do eu que, em trânsito, assim como Cipriano em sua furgoneta, busca novas possibilidades dialógicas, que podem ou não ser realizadas.

O drama humano retratado no romance de Saramago, no qual se realiza apenas uma parte do duplo movimento que constitui a subjetividade, prevalecendo a dominação do outro (Centro) sobre o eu (Cipriano Algor e demais personagens), permite interpretar nessa incompleta constituição subjetiva uma alegoria do processo histórico da modernidade, em que tem lugar a uma crescente animalização e objetificação do sujeito, o que Bakhtin (2003) denomina, do ponto de vista humano, como dialética do sujeitoobjeto. A tensão do drama se resolve quando o sujeito, em determinado momento da narrativa, resiste a esta relação de dominação, abolindo-a de seu convívio, ou seja, realizando o movimento de evasão tanto do que era tido como lugar identitário do eu (Olaria) quanto do que foi identificado como lugar de exploração/dominação do outro (Centro). O desfecho da narrativa pode, ainda, denotar que esta evasão total não é possível na modernidade, visto que, após este movimento de retirada das personagens, a narrativa se encerra. Deixa-se, deste modo, lugar a um vazio que ao mesmo tempo se encerra na alegoria e é sugerido por ela, abrindo espaço para a interpretação do que afinal vem após esse estado de coisas que é representado no romance como referência a questões que estão para além dele.

De modo geral, a análise da representação antagônica do espaço constituído pelo Centro e ora descrita destaca a maneira como a alteridade é a pedra de toque da questão moderna, pois o espaço opressor representado pelo Centro se constitui de modo a forçar os sujeitos a se dirigirem progressivamente para um apagamento de si e uma mercantilização das relações que outrora negariam a lógica produtiva do capital.

Por fim, destacamos que a leitura ora proposta em nenhum momento esgota as possibilidades de leitura referente à obra primária, pois tanto o duplo, quanto a alegoria e o antagonismo de um espaço são temáticas relacionadas a diversas estruturas, como a 
Filosofia, a Cultura, a Antropologia e a História, relações que devem ser elaboradas em leituras vindouras.

\section{Referências}

AMORIM, Marília. O pesquisador e seu outro: Bakhtin nas ciências humanas. São Paulo: Musa Editora, 2004.

AUGÉ, Marc. Não-lugares: Introdução a uma antropologia da supermodernidade. Trad. Maria Lúcia Pereira. Campinas: Papirus, 1994.

BAKHTIN, Mikhail. "O autor e a personagem na atividade estética”. In: Estética da criação verbal. Trad. Paulo Bezerra. São Paulo: Martins Fontes, 2003.

. "O problema do texto na linguística, na filologia e em outras ciências humanas". In: Estética da criação verbal. Trad. Paulo Bezerra. São Paulo: Martins Fontes, 2003a, p. 307-336.

. "Reformulação do livro sobre Dostoiévski". In: Estética da criação verbal. Trad. Paulo Bezerra. São Paulo: Martins Fontes, 2003b, p. 337-358.

. "O discurso na poesia e o discurso no romance". In: Teoria do romance I. A estilística. Trad. Paulo Bezerra. São Paulo: Editora 34, 2015.

. "O falante no romance". In: Teoria do romance I. A estilística. Trad. Paulo Bezerra. São Paulo: Editora 34, 2015 a.

BAUDRILLARD, Jean. El outro por sí mismo. Trad. Joaquín Jordá. Barcelona, Espanha: Anagrama, 1988.

BEZERRA, Paulo. Prefácio à segunda edição brasileira de Problemas da poética de Dostoiévski. In: BAKHTIN, Mikhail. Problemas da poética de Dostoiévski. Rio de Janeiro: Forense Universitária, 2002.

BRAVO, Nicole Fernandez. Duplo. In: BRUNEL, Pierre (Org.). Dicionário de mitos literários. Rio de Janeiro: José Olympio, 1998 (1988).

CARROLL, Lewis. Alice's adventures in wonderland and through the looking-glass. New York: Sterling Publishing, 2012.

CHAUÍ, Marilena. Convite à filosofia. São Paulo: Ática, 2000. In: http://home.ufam.edu.br/andersonlfc/Economia_Etica/Convite\%20\%20Filosofia\%20\%20Marilena\%20Chaui.pdf (e-book). Acesso em: Manaus, 16 de agosto de 2018, às $15 \mathrm{~h} 05 \mathrm{~min}$. 
CHEVALIER, Jean; GHEERBRANT, Alain. Dicionário de símbolos: (mitos, sonhos, costumes, gestos, formas, figuras, cores, números). Trad. Vera da Costa e Silva [et at.] 19. ed. Rio de Janeiro: José Olympio, 2005 (1982).

CAVALHEIRO, Juciane. Literatura e enunciação. Manaus: UEA Edições, 2010.

. O eu e o outro na enunciação de Jorge Luis Borges. Bakhtiniana: Revista de Estudos do Discurso. ISSN 2176-4573, [S.1.], v. 10, n. 1, p. Port. 75-86 / Eng. 80-92, abr. 2015. ISSN 2176-4573. In:

https://revistas.pucsp.br/bakhtiniana/article/view/20825/16668. Acesso em: Manaus, 16 de julho de 2020.

FLORES, Valdir do Nascimento; TEIXEIRA, Marlene. Introdução à linguística da enunciação. 2. ed. São Paulo: Contexto, 2010 (2005).

HALL, Stuart. “A questão multicultural”. In: Da diáspora: identidade e mediações culturais. Belo Horizonte: UFMG, 2003.

Identidade cultural na pós-modernidade. São Paulo: DP\&A, 2002.

PLATÃO. A república. Trad. Enrico Corvosieri. São Paulo: Nova Cultural, 2000 (380 a.c?).

REIS, Carlos. Diálogos com José Saramago. Lisboa: Caminho, 1998. SARAMAGO, José. A caverna. São Paulo: Cia das Letras, 2000.

. O homem duplicado. São Paulo: Cia das Letras, 2008.

SEIXO, Maria Alzira. O essencial sobre José Saramago. Lisboa: Imprensa Nacional Casa da Moeda, 1987.

Recebido em: 27/05/2019

Aceito em: 18/06/2020 